\title{
Hospitals, Market Share, and Consolidation
}

\section{Citation}

Cutler, David M., and Fiona Scott Morton. 2013. "Hospitals, Market Share, and Consolidation." JAMA 310 (18) (November 13): 1964. doi:10.1001/jama.2013.281675.

\section{Published Version}

doi:10.1001/jama.2013.281675

\section{Permanent link}

http://nrs.harvard.edu/urn-3:HUL.InstRepos:32306634

\section{Terms of Use}

This article was downloaded from Harvard University's DASH repository, and is made available under the terms and conditions applicable to Other Posted Material, as set forth at http:// nrs.harvard.edu/urn-3:HUL.InstRepos:dash.current.terms-of-use\#LAA

\section{Share Your Story}

The Harvard community has made this article openly available.

Please share how this access benefits you. Submit a story.

Accessibility 


\section{Special Communication \\ Hospitals, Market Share, and Consolidation}

David M. Cutler, PhD; Fiona Scott Morton, PhD

A large reduction in use of inpatient care combined with the incentives in the Affordable Care Act is leading to significant consolidation in the hospital industry. What was once a set of independent hospitals having arms-length relationships with physicians and clinicians who provide ambulatory care is becoming a small number of locally integrated health systems, generally built around large, prestigious academic medical centers. The typical region in the United States has 3 to 5 consolidated health systems, spanning a wide range of care settings, and a smaller fringe of health care centers outside those systems. Consolidated health systems have advantages and drawbacks. The advantages include the ability to coordinate care across different practitioners and sites of care. Offsetting this is the potential for higher prices resulting from greater market power. Market power increases because it is difficult for insurers to bargain successfully with one of only a few health systems. Antitrust authorities are examining these consolidated systems as they form, but broad conclusions are difficult to draw because typically the creation of a system will generate both benefit and harm and each set of facts will be different. Moreover, the remedies traditionally used (eg, blocking the transaction or requiring that the parties divest assets) by antitrust authorities in cases of net harm are limited. For this reason, local governments may want to introduce new policies that help ensure consumers gain protection in the event of consolidation, such as insurance products that charge consumers more for high-priced clinicians and health care centers, bundling payments to clinicians and health care organizations to eliminate the incentives of big institutions to simply provide more care, and establishing area-specific price or spending targets.

JAMA. 2013;310(18):1964-1970. doi:10.1001/jama.2013.281675
Author Affiliations: Department of Economics, Harvard University, Cambridge, Massachusetts (Cutler); Yale University School of Management, New Haven, Connecticut (Scott Morton).

Corresponding Author: David M. Cutler, PhD, Harvard University Department of Economics, 230 Littauer Center, Cambridge, MA 02138 (dcutler@harvard.edu).
$\mathrm{O}$ ver the last few decades, what was once an independent hospital has increasingly become a health system centered on inpatient institutions. Many health systems in the market today generally have 1 or more academic medical center "hubs," surrounded by other community or short-term acute hospital "spokes," and ownership interest or close affiliations with physicians, clinics, rehabilitation facilities, and other health care practitioners and organizations. Because hospitals are often the center of the institution, medical care across the continuum is effectively coming under the direct or indirect control of institutions that provide inpatient care.

Policy makers both revere and revile these health systems. On the one hand, lack of coordination has long been seen as a key failure of US health care. ${ }^{1}$ Integrated health systems have the capacity to address the quality deficiencies resulting from lack of coordination. On the other hand, health systems can become so large that they are able to increase prices, harming consumers and taxpayers. Thus, there are increasing calls for greater antitrust scrutiny of hospital systems. ${ }^{2}$

Which of these views is right? Should big health systems be treated the same as retailers or Internet companies that merge to become dominant in their markets? Or should growth of health care systems be encouraged in the name of efficiency and better outcomes? In this Special Communication, we present data on the growth of integrated systems, discuss the potential benefits and harms of integration, and consider possible remedies.

\section{Methods}

\section{Analysis of Hospital Markets}

Our analysis of hospital markets is based on data from the American Hospital Association (AHA). We used data on nonfederal, shortterm general and specialty hospitals that have facilities and services available to the public.

Information on hospital days and the number of hospitals over time was derived from the AHA Chartbook. ${ }^{3}$ To understand how hospital markets have become structured, we analyzed information for the 306 hospital referral regions (HRRs) spanning the country, using data from 2010. Hospitals were grouped into systems, with the hospitals in each system treated as an entity. We considered systems only within the same HRR. If a parent system had multiple hospitals in different HRRs, each HRR was considered separately so that we could adequately assess the competitive environment in each HRR.

To characterize the competitive environment in the HRR, we used 2 metrics. First, we considered the share of admissions that are captured by a certain number of institutions (eg, the share of admissions in the largest 3 hospitals or hospital systems). Second, we calculated for each market using the Herfindahl-Hirschman Index ${ }^{4}(\mathrm{HHI})$ of concentration. This variable is the sum of the squared market share of each hospital or hospital system in the market multiplied by 10000 . For example, a market with only 1 inpatient institution would have a squared market share equal to 1 , and thus an $\mathrm{HHI}$ of 10000 . Conversely, a mar- 


\section{Figure 1. Trends in Use of Short-term Hospitals, 1981-2011}

A Inpatient days at short-term acute hospitals

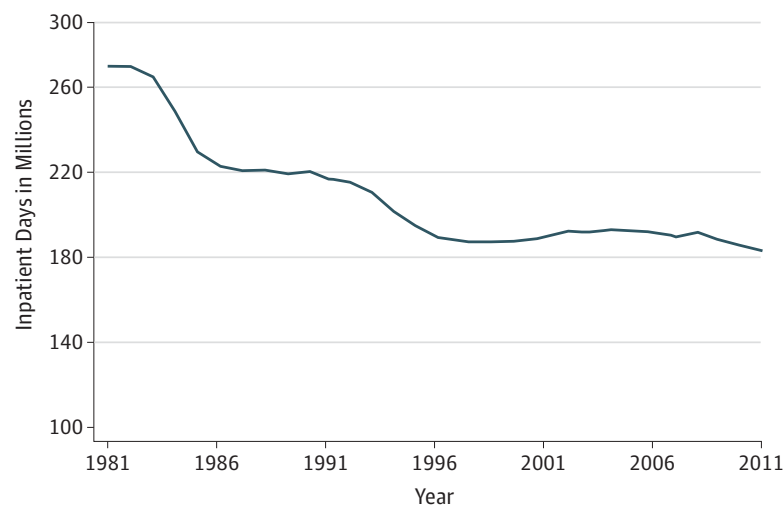

ket with a large number of small institutions would have a small sum of squared market shares, and thus an $\mathrm{HHI}$ near $\mathrm{O}$. As is standard, we considered markets highly concentrated if they have an $\mathrm{HHI}$ greater than 2500 , moderately concentrated if they have an HHI between 1500 and 2500 , unconcentrated if they have an $\mathrm{HHI}$ between 100 and 1500 , and highly competitive if they have an $\mathrm{HHI}$ below $100 .^{5}$

\section{Horizontal and Vertical Consolidation}

Horizontal consolidation involves hospitals merging with other hospitals. Throughout the article, the term health care provider entity refers to a hospital, outpatient center, physician group, clinic, rehabilitation center, nursing home, home health agency, or any other entity that provides health care to patients and sets or negotiates prices. Vertical consolidation involves hospitals consolidating with other health care provider entities. We used a variety of data sources to assess each. The number of hospitals in systems was from the AHA and included the universe of short-term hospitals ( $N=4973)$. Data on hospital mergers and acquisitions were from Irving Levin Associates and cover the entire market. ${ }^{6}$ The trend in the $\mathrm{HHI}$ was reported by Gaynor ${ }^{7}$ based on calculations from AHA data.

The number of hospitals owning postacute and other outpatient facilities was from the AHA Chartbook ${ }^{3}$ and included the full sample of hospitals noted above. Data on ownership of physician practices was from Medical Group Management Association surveys. ${ }^{8}$

\section{Hospital Bond Ratings}

Data on hospital bond ratings were not systematically collected; we instead used data from Moody's on a sample of hospitals. ${ }^{9}$ A highgrade bond was defined as a bond rated $\mathrm{Aa} 3$ or higher (equivalent to an AA- at Fitch and Standard and Poor's). ${ }^{10}$ Such bonds are more likely to be repaid than lesser-rated bonds. The top rating is termed prime and corresponds to a bond rated Aaa at Moody's (equivalent to an AAA at Fitch and Standard and Poor's).

\section{Results}

\section{Hospital Use}

Hospital use and the number of short-term acute hospitals have declined between 1981 and 2011 (Figure 1). During the entire period, hos-
B Short-term acute care hospitals

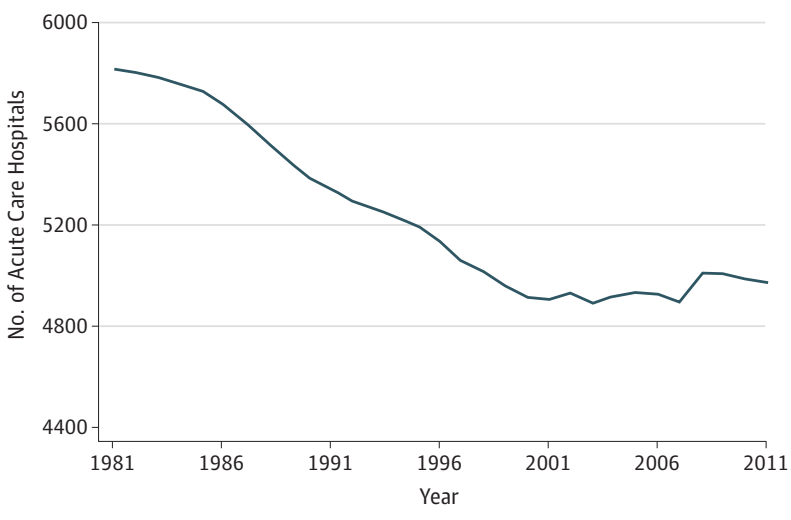

\begin{tabular}{|c|c|}
\hline & Percentage $^{a}$ \\
\hline \multicolumn{2}{|l|}{ Hospital data $(\mathrm{N}=4973)^{\mathrm{b}}$} \\
\hline Hospitals in a health system & 60 \\
\hline No. of hospitals in typical system & 3.2 \\
\hline \multicolumn{2}{|l|}{ Offering nonhospital services } \\
\hline Home health care & 60 \\
\hline Skilled nursing facilities & 37 \\
\hline Hospice services & 62 \\
\hline Assisted living care & 15 \\
\hline \multicolumn{2}{|l|}{ Mergers and acquisitions ${ }^{\mathrm{b}, \mathrm{c}}$} \\
\hline No. of deals & 432 \\
\hline No. of hospitals & 832 \\
\hline \multicolumn{2}{|l|}{ Ownership of physician practice ${ }^{d}$} \\
\hline By hospitals & 49 \\
\hline By physicians & 41 \\
\hline Other $^{\mathrm{e}}$ & 10 \\
\hline \multicolumn{2}{|c|}{ a The sources for these data only reported percentages. } \\
\hline \multicolumn{2}{|c|}{ b Sample is composed of US short-term acute hospitals. } \\
\hline \multicolumn{2}{|c|}{$\begin{array}{l}\text { ' Numbers (instead of percentages) are reported for these } 2 \text { variables because } \\
\text { some hospitals are represented more than once. Data for mergers and } \\
\text { acquisitions are for } 2007-2012 \text {. }\end{array}$} \\
\hline \multicolumn{2}{|c|}{ d There were 62245 physicians included in this analysis. } \\
\hline \multicolumn{2}{|c|}{$\begin{array}{l}\text { e Indicates nonphysician and nonhospital investors; however, survey } \\
\text { tabulations do not delineate the bulk of these separately. }\end{array}$} \\
\hline
\end{tabular}

pital days declined by $33 \%$ despite a growing and aging population. Coincident with the decline in use, more than $15 \%$ of hospitals closed.

Hospital bond ratings reflect the tenuous economic circumstances. Of 494 hospitals with debt rated by Moody's, only $18 \%$ received a high grade; none were rated prime.

\section{Extent of Consolidation}

Both horizontal and vertical consolidation has increased in health care. Sixty percent of hospitals are now part of health systems, up 7 percentage points from a decade ago. The average local system has 3.2 independent hospitals. From 2007 to 2012, 432 hospital merger and acquisition deals were announced, involving 835 hospitals.

Expanding vertically, hospitals increasingly own physician practices and health care entities that provide postacute care (Table 1). 

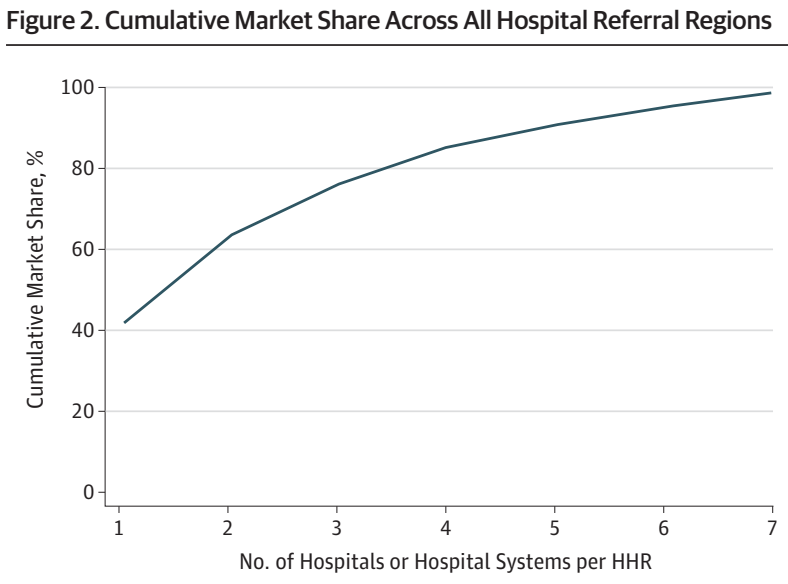

All hospitals in the hospital referral region (HRR) belonging to the same system are grouped together as 1 institution. The cumulative market share is based on the number of inpatient days in each facility.

From 2004 to 2011, hospital ownership of physician practices increased from $24 \%$ of practices to $49 \%$. Postacute care health care organizations and services are also increasingly affiliated with hospitals. Sixty percent of hospitals offer home health services, $37 \%$ have skilled nursing facilities, $62 \%$ own hospice services, and $15 \%$ provide assisted living options.

\section{Hospital Market Organization}

Across the 306 HRRs, the largest market participant (usually a system) accounted for a mean of $42 \%$ of all the hospital inpatient days (median of $38 \%$ ). In nearly $68 \%$ of HRRs, the largest participant was or contained at least 1 academic medical center.

Most HRRs were characterized by multiple large hospitals or hospital systems, although not a large number of such systems (Figure 2). On average, the top 3 share leaders in an area accounted for $77 \%$ of hospital admissions, and the top 5 hospitals or systems accounted for $88 \%$. A general characterization of the typical hospital market in the United States is that it has 1 dominant system, 2 to 3 smaller systems, and a residual fringe of smaller institutions.

Figure 3 shows the $\mathrm{HHI}$ in each HRR. Panel $\mathrm{A}$ is a standard US map; panel $B$ is modified so that the size of each HRR is proportional to the population. More populous areas are less concentrated on average. Even still, concentration is pervasive. Nearly half ( $n=150$ ) of hospital markets in the United States are highly concentrated, another third ( $n=98$ ) are moderately concentrated, and the remaining one-sixth $(n=58)$ are unconcentrated. No hospital markets are considered highly competitive.

The extent of hospital concentration has increased over time. The hospital HHI has increased by $40 \%$ since the mid-1980s, changing from a market with on average 5 independent firms (there were $>5$ independent hospitals, but approximately 5 major ones) to a market with approximately 3 independent firms.

\section{Discussion}

The quantity of hospital care demanded has declined over time; inpatient days decreased by one-third between 1981 and 2011. This

\section{Figure 3. Hospital Referral Region Concentration Across the United States}

A Hospital referral regions

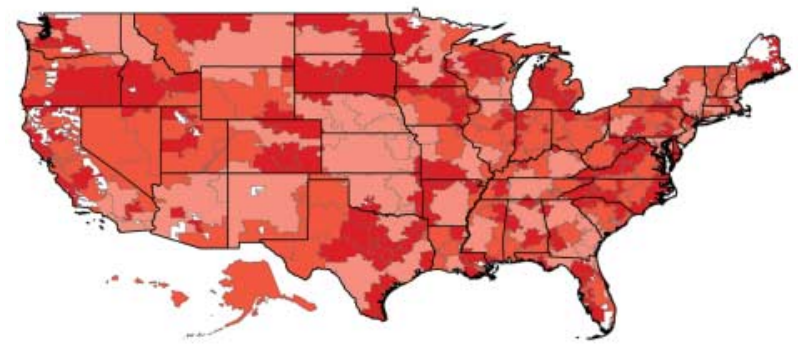

B Hospital referral regions proportional to the population

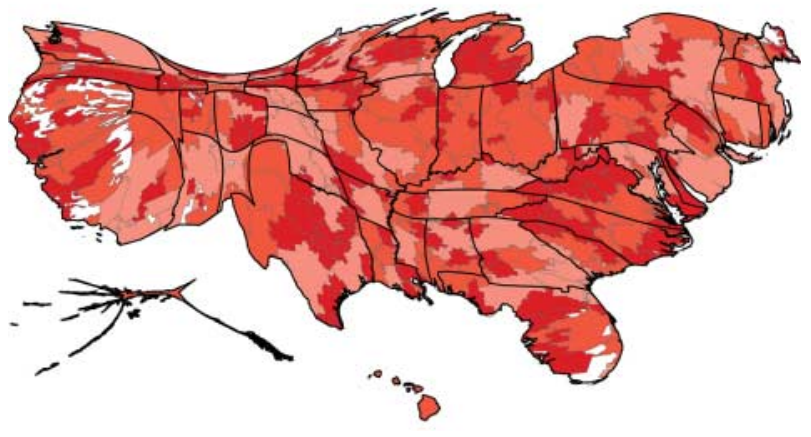

Herfindahl-Hirschman Index (HHI) of Market Concentration

Unconcentrated (HHI 100 to $<1500)$

Moderately concentrated ( $\mathrm{HHI} 1500$ to $<2500)$

Highly concentrated $(\mathrm{HHI} \geq 2500)$

Not located in any hospital referral region

The designation of concentration is based on the $\mathrm{HHI}$, with categories of concentration defined by the Department of Justice and Federal Trade Commission. ${ }^{5}$ Both maps show that high concentration of hospitals is pervasive across the country. There are no hospital referral regions with a "highly competitive" HHI $(<100)$.

decline is generally attributed to a few factors. ${ }^{11}$ The first factor is technological innovations (eg, minimally invasive surgery) that lessen the need for inpatient care. Economic considerations are also driving reduced hospital use. Hospitals are more expensive than ambulatory surgery centers or outpatient facilities. Thus, patients or insurers with a financial stake in where patients receive care increasingly prefer less intensive settings.

The reduction in demand for hospital care has not affected all institutions the same way. Even as inpatient demand has declined, there is no realistic substitute to the tertiary care hospital for patients needing advanced, technology-driven treatment. The learning curve for individual physicians and surgical teams means that the large hospital in a city or region will frequently offer better care options to patients. As the advanced treatments become ever more sophisticated and expensive, they become increasingly concentrated in fewer inpatient institutions. Furthermore, the research and education focus of many large teaching hospitals may result in their offering more innovative treatments. Large teaching hospitals also have greater endowment and revenue streams than smaller hospitals, making them a valuable source of capital when small hospitals need to invest in the facility, equipment, or information systems. 
Thus, flagship academic medical centers offering perceived higher quality care often wield enormous market power. Notwithstanding the observed decline in hospital days used, consumers highly value the option of obtaining care at these hospitals, and thus highly value insurance that allows access to these institutions. ${ }^{12}$ Furthermore, a patient who has a serious illness and also is well insured will seek out these hospitals with little regard for price.

A small hospital with fewer patients may gain financially by joining an academic medical center's system. The result is pressure for small institutions to combine with large institutions, and even for large institutions to merge with each other. For small hospitals, access to capital is made easier by merging with a large hospital, and payment rates are often higher. For large hospitals, consolidation with small hospitals increases the inpatient base to support their high fixed costs. Consolidation with other large hospitals can allow the new entity to negotiate higher prices with insurers, who would otherwise play large institutions against each other.

Upcoming policy changes seem likely to further reinforce the pressure to consolidate. The Affordable Care Act (ACA) reduced the growth of Medicare hospital reimbursement by about 1.5 percentage points annually, the latest in a series of payment reductions stretching back many years. ${ }^{13}$ Cash-strapped state governments have reduced fees to inpatient institutions. The presumed revenue enhancement from expanded insurance coverage may not occur if states choose not to adopt the ACA Medicaid offer; 26 states have stayed out initially. ${ }^{14}$ These financial challenges will make it even more difficult for weaker hospitals to survive on their own.

\section{Potential Benefits and Harms of Consolidation for Consumers} Large health systems may create benefits as well as harms (Table 2). On the benefit side, large health systems may be able to provide higher quality care. Studies have shown a clear relationship between volume and outcome for many surgical procedures. ${ }^{15,16} \mathrm{Con}$ solidation can increase volume for specialized services and thus improve quality. Similarly, larger systems are able to spread the financial burden of high-cost investments (eg, electronic medical records; EMRs) better across their constituent members.

Consolidation may also contribute to cost savings. Indeed, this is the rationale for accountable care organizations (ACOs). Care provision may be made more efficient if one parent health organization group oversees and controls the continuum of care. For example, different practitioners and health centers with a shared medical record may find it easier to reduce duplication and plan across settings. Additionally, the institution as a whole may consider care across settings to make it more efficient (eg, a home visit from a nurse as part of rehabilitation may prevent another hospital admission or an expensive drug may prevent an even more expensive hospital admission). For this reason, many of the least resource-intensive health centers in the country are integrated care organizations. ${ }^{17}$

Empirical studies on cost savings from consolidation are mixed. ${ }^{18,19}$ Although some studies show cost savings after a consolidation, such savings require significant integration of different parts of the health system, which does not always occur. Thus, this rationale for consolidation remains important theoretically but tentative, and likely complex, empirically.

One of the challenges of hospital consolidation is concern about increasing prices. For instance, consider a prototypical mar-

\begin{tabular}{|c|c|c|}
\hline Claim & Example & $\begin{array}{l}\text { Literature } \\
\text { to Date }\end{array}$ \\
\hline \multicolumn{3}{|l|}{ Benefits } \\
\hline \multicolumn{3}{|l|}{ Quality improvements } \\
\hline $\begin{array}{l}\text { Large size of any } 1 \text { service } \\
\text { (eg, hospital) improves } \\
\text { quality of care. }\end{array}$ & $\begin{array}{l}\text { Surgeon specializing in } \\
\text { hand surgery has better } \\
\text { outcomes. }\end{array}$ & Robust \\
\hline $\begin{array}{l}\text { Larger size allows for more } \\
\text { costly investments. }\end{array}$ & $\begin{array}{l}\text { Spreading financial burden } \\
\text { allows for investment in } \\
\text { electronic medical records. }\end{array}$ & Robust \\
\hline $\begin{array}{l}\text { Cost savings: Coordination of } \\
\text { care is improved when hospi- } \\
\text { tals join with complementary } \\
\text { providers (eg, physician or- } \\
\text { ganizations, rehabilitation } \\
\text { centers, nursing homes, etc). }\end{array}$ & $\begin{array}{l}\text { For a complex procedure, } 1 \\
\text { case manager can work } \\
\text { with patient through pre- } \\
\text { surgery, surgery, and post- } \\
\text { surgery, managing contin- } \\
\text { ued coordination across } \\
\text { various clinicians. }\end{array}$ & Minimal \\
\hline \multicolumn{3}{|l|}{ Harms } \\
\hline $\begin{array}{l}\text { Higher prices: Clinicians gain } \\
\text { market power through con- } \\
\text { solidation and raise prices to } \\
\text { payers. }\end{array}$ & $\begin{array}{l}\text { Because consolidation re- } \\
\text { duces the number of hospi- } \\
\text { tal systems from } 5 \text { to } 3, \\
\text { payers cannot afford to } \\
\text { exclude } 1 \text { system from a } \\
\text { product, and thus hospitals } \\
\text { can demand higher prices. }\end{array}$ & Robust \\
\hline $\begin{array}{l}\text { Less innovation: Innovation } \\
\text { suffers when clinicians face } \\
\text { less competition. }\end{array}$ & $\begin{array}{l}\text { No investment in uniform } \\
\text { protocols for postsurgical } \\
\text { care because no alternative } \\
\text { for consumer. Slow to } \\
\text { adopt new surgical tech- } \\
\text { niques because of familiar- } \\
\text { ity with current ones. }\end{array}$ & Minimal \\
\hline
\end{tabular}

ket that once had 15 independent hospitals, roughly the average number in a market in 2010. If an insurer wanted most, but not all, hospitals in its network, it could rationally bargain over price with the hospitals in the area and be willing not to come to an agreement with a few hospitals asking for very high prices. Even though some consumers may object to the omission of those hospitals from the insurer's network, most patients would be able to find a substitute hospital somewhere in the large set of choices offered in the network.

In contrast, if the hospitals consolidate into only 3 large systems, insurers will find it difficult to exclude even 1 system from the plan because that would mean many hospitals would be excluded from the network, with at least 1 likely being a major medical center. Consumers (and employers) may not want to purchase a plan that excludes such a large part of the market. Thus, with no system plausibly able to be excluded from the insurer's network, each system can charge insurers a higher price. These price increases affect consumers directly in their out-of-pocket payments when they buy insurance and when they pay taxes that fund public insurance programs.

Nonprofit hospitals traditionally argue that consolidation is reasonable because their nonprofit status means they will not increase prices. In contrast, the data demonstrate that ownership status is not a deterrent to price increases, and prices are just as high in nonprofit as in for-profit organizations. ${ }^{20}$ Nonprofit hospitals appear to share the goal of maximizing profit; they simply distribute the profits in a different way by providing unprofitable services, supporting research, underwriting free care, and building up reserves (instead of distributing profits to shareholders).

Consistent with the theory, the recent wave of hospital consolidation has led to price increases for hospital care. A recent summary ${ }^{7}$ 
Figure 4. Defining a Safety Zone in the Statement of Antitrust Enforcement Policy Regarding Accountable Care Organizations (ACOs) Participating in the Medicare Shared Savings Program

Qualifications for ACO Inclusion in the Antitrust Safety Zone

ACOs within the safety zone are considered not to raise antitrust concerns.

1. Combined share of service

The combined share of common services provided $^{2}$ by participants in an ACO (physician, physician group; inpatient facility; outpatient facility) mus be $\leq 30 \%$ of each service in each participant's primary service area. ${ }^{\mathrm{b}}$

Dominant participant limitation

If an ACO includes a participant with $>50 \%$ share in its primary service area of any service that no other ACO participant provides to patients in the primary service area, the ACO participant must be nonexclusive to the ACO.

Rural provider exception

An ACO may include a physician or physician group in a rural countyc even if inclusion of the participant causes the ACO to exceed the combined $30 \%$ share of service qualification. The rural participant must be nonexclusive to the ACO. An ACO may also include rural hospitals on a nonexclusive basis.
The Department of Justice and Federal Trade Commission released antitrust guidance for hospitals participating in the ACO program. ${ }^{25}$ Antitrust safety is provided to institutions with a low share of patients and nonexclusive access to their facilities, or to larger institutions with nonexclusive access in some settings. Being outside the antitrust safety zone does not indicate that a consolidation will be opposed. Rather, it indicates that a greater degree of scrutiny will be applied.

a Accountable care organization services include physician services (categorized by physician specialty); inpatient services (categorized by major diagnostic criteria); and outpatient services (categorized by Centers for Medicare \& Medicaid Services outpatient facilities definitions).

${ }^{\mathrm{b}}$ The primary service area for each ACO participant is the minimum number of contiguous zip codes needed to reach at least $75 \%$ of the participant's patients.

${ }^{\mathrm{C}} \mathrm{A}$ physician or physician group with a primary office in a zip code classified as "isolated rural" or "other small rural." cites 8 studies that show price increases in the range of $10 \%$ to $40 \%$ due to mergers. Similarly, the attorney general of Massachusetts has shown that prices for medical services vary substantially across hospitals and other health care centers, with little relationship between quality and price but a strong relationship between institutional reputation and price. ${ }^{21}$

Another potential adverse effect of consolidation is lack of innovation in products and processes. With respect to product innovation, most studies find that investment in new technologies is positively correlated with profits. ${ }^{22}$ Process innovations, however, seem to decline with market power consolidated in a few institutions. Organizations with market power often lack the incentive to develop simple items such as checklists and uniform protocols that deliver services in newer, more efficient ways. ${ }^{23}$ Such changes are difficult, and managers of large, profitable organizations might conclude that they do not need to undertake them.

\section{Antitrust Concerns}

The degree of consolidation induced by recent mergers is significant enough to warrant antitrust scrutiny. The attempted merger in 2011 of AT\&T and T-Mobile provides a helpful benchmark; the proposed merger would have placed 96 of the top 100 markets into the highly concentrated category, which was one of the reasons it was blocked by the Department of Justice. ${ }^{24}$ Health care is not as concentrated as cellular telephone service would have been, but many markets are in the noncompetitive range.

In considering the response of antitrust authorities to transactions in the health care sector, a fundamental distinction needs to be made between the effects of consolidation on public and private payers. Public payers (such as Medicare and Medicaid) set prices and do not negotiate with hospitals and other health care organi- zations. Because of their large patient volume, essentially all hospitals accept Medicare and Medicaid rates. Thus, if large health care organizations become more efficient and lower treatment costs, public payers can readily leverage these savings by reducing the amount they reimburse. The reductions in hospital update factors (by about 1.5 percentage points annually ${ }^{13}$ ) in the ACA are an example of how this could play out.

Private payers, in contrast, need to negotiate reimbursement rates with health care organizations. With less negotiating leverage as a result of consolidation, private insurers may find it more difficult to leverage cost savings into reduced reimbursement for the health care organization. An integrated health system may reduce costs by $10 \%$ to $20 \%$, but it is uncertain whether doing so will translate into lower charges to private insurers.

For this reason, antitrust agencies are paying increasing attention to the possible effect of consolidation on private payers. The Justice Department and Federal Trade Commission recently issued guidance on what transactions would fall into a safe harbor as hospitals transform into ACOs (Figure 4) ${ }^{25}$ Consolidation will be in the safety zone if the consolidating parties have fewer than $30 \%$ of the market in their relevant service area and are not exclusive health care provider entities to some ACOs, if they are larger but there are no other ACOs in the area and they are not exclusive to the ACO, or if they are in rural areas in which consolidation will necessarily be high. The antitrust authorities have been supported by the courts; a recent US Supreme Court decision gave the Federal Trade Commission greater ability to police hospital mergers. ${ }^{26}$

Antitrust analysis involves several principles. An important principle is that the antitrust law exists to protect competition, not particular competitors. The sole question for antitrust agencies in considering whether health systems would become too large with a 
particular consolidation is whether consumers will be better or worse off as a result. The financial status of any health care organization is immaterial, except insofar as it affects consumer welfare.

A second important antitrust principle is that all effects of a transaction must be analyzed and balanced to determine the net effect on consumers. In a situation in which consumers are helped by some aspects of a consolidation and harmed by others, the decision about whether the consolidation should be permitted should be based on whether the benefits significantly outweigh the harms. Thus, simply demonstrating that clinicians and health care provider entities have increased access to a common EMR in a large system, for example, will not outweigh the harm from higher prices unless the EMR is being used to create a large enough consumer benefit.

Third, a baseline criterion for evaluating efficiencies from a consolidation is whether those efficiencies could be achieved in ways that do not lessen competition. For instance, although there may be benefits of harmonizing EMRs, can those benefits be achieved by a simple contract or a clinical affiliation rather than a merger? If yes, the agencies will not look favorably on arguments that increased market power due to the merger of large institutions is justified.

The level of benefits and harms in a given situation is likely to vary based on the size of the community. In large metropolitan areas, economies of scale and vertical integration may be achievable in a large system that is not dominant because the market is so large. The agencies will likely be skeptical of the need for extreme consolidation in such an area.

In smaller communities, efficiency gains of the same type may require consolidation that includes hospitals and other health care organizations comprising a larger fraction of the market. Such consolidation could cause large price increases. In that case, the balancing test of the agencies will be more difficult. For example, does the increase in quality of care offset the higher prices? Determining the best outcome in such a situation will require careful analysis.

\section{Possible Remedies}

Striking the right balance in health care will be difficult. Consolidation has many possible advantages but also many potential disadvantages.

To the extent that some intervention in health care markets is appropriate, traditional antitrust enforcement focuses on blocking the proposed merger or on divestiture of the hospital, physician group, or other entity that is generating the competitive concerns. The US Department of Justice and the Federal Trade Commission may also use what are termed conduct remedies, which are not structural in nature, but rather behavioral. An example of this type of remedy is a restriction on the type of contracts into which the combined firm may enter. The agencies tend not to accept remedies of the form in which the combined firm promises not to raise prices because these would be difficult to enforce and therefore unlikely to work, and would also involve expensive monitoring by agency personnel.

Given the limited options available by using antitrust enforcement, state and federal health care agencies may choose to pursue other avenues to enhance the benefits of consolidation relative to the costs. The following 3 avenues may be appropriate.

\section{Insurance Changes}

A first direction is to encourage more selective contracting between insurers and health systems than simply inclusion or exclu- sion of a system from a network. Even though all health systems may need to be in an insurer's network, they do not need to have the same cost sharing for consumers. Thus, routine surgery could involve higher consumer cost sharing if provided at the dominant health system in a market than in a less expensive one. This policy is termed $a$ tiered network, analogous to the tiering of pharmaceuticals in a formulary. This is already common in numerous health care plans.

Dominant institutions are likely to oppose this development because they price routine care at rates above cost, and therefore tiering threatens their revenue model. It is likely that dominant hospitals will prefer insurers to cover all their services at the same cost sharing, even though this may raise the total cost of care. If policy wishes to circumvent this, it may need to prohibit health care provider entities from insisting on these provisions (eg, by prohibiting the contract requirement that all services be covered on an even basis).

\section{Bundled Payments}

A second direction for policy is to change the incentives for health systems to ones that strongly encourage cost savings, not just the provision of profitable interventions. Dominant systems are profitable in part because they provide well-reimbursed procedures at very high rates. Reducing the profits from these procedures can limit the money to be made through excessive procedures, thus reducing the dominant system's market power.

The future of the ACA is critical here. Some of the consolidation in hospital care has been driven by the promise of reforms in the ACA that would reduce the gains resulting solely from providing more intensive care. Indeed, this was the basis of the ACO program. Having fostered consolidation as a strategy for increased efficiency, it is incumbent upon the Centers for Medicare \& Medicaid Services to follow through with rapid transition into alternative payment mechanisms. Similarly, private insurers will need to follow the ACA lead, as many are starting to do. For example, Arkansas state legislation requires episode-based payment by Medicaid and private insurers for a small but increasing number of conditions. ${ }^{27}$

\section{Price or Spending Targets}

A third approach, if there is no other way to obtain good care except through monopoly organizations, is for policy makers to regulate prices or total spending. Price regulation of natural monopolies has a long history in the United States, and Medicare and Medicaid have used administrative prices for many years. Price regulation could expand to private insurers (eg, by requiring dominant ACOs to sell their subspecialized services to every insurer or other ACOs at reasonable rates).

A substitute for price regulation is setting overall expenditure targets. Oregon has started such a policy in its Medicaid program. In exchange for additional federal funds, Oregon agreed to reduce the per capita medical trend by 2 percentage points. In turn, Oregon has organized Medicaid health care provider entities into coordinated care organizations capable of accepting bundled rates increasing at a low rate. ${ }^{28}$

A different approach is being pioneered in Massachusetts, which has set an overall expenditure growth target for medical care as a whole. ${ }^{29}$ The target is for overall costs (both public and private) to increase at the rate of the state economy or slightly below it. Unlike in Oregon, the penalties for nonadherence to the target are not fully specified in law. Even still, the legislation is a significant model. 


\section{Conclusion}

A central economic question about the emerging health system is whether consolidation of large hospital institutions is beneficial or harmful. The answer is not always the same because it depends on the environment in which consolidation occurs, who is consolidating, how large each organization is in its different markets, and whether the combined entity improves quality of care. Having policy makers be smart about how hospitals and other health care institutions are allowed to consolidate is critical to ensuring that the population is receiving the best care possible at reasonable, affordable prices.

\section{ARTICLE INFORMATION}

Author Contributions: Dr Cutler had full access to all of the data in the study and takes responsibility for the integrity of the data and the accuracy of the data analysis. The order of the authors is alphabetical and both authors contributed equally. Study concept and design: Cutler, Scott Morton. Acquisition of data: Cutler, Scott Morton. Analysis and interpretation of data: Scott Morton. Drafting of the manuscript: Cutler, Scott Morton. Critical revision of the manuscript for important intellectual content: Cutler, Scott Morton. Statistical analysis: Cutler, Scott Morton. Administrative, technical, or material support: Cutler, Scott Morton.

Study supervision: Scott Morton.

Conflict of Interest Disclosures: The authors have completed and submitted the ICMJE Form for Disclosure of Potential Conflicts of Interest. Dr Cutler reported receiving institutional grant support from the National Institutes of Health; and honoraria, reimbursement for travel expenses, speaking fees, and reimbursement for parking from several universities, associations, organizations, and companies. Dr Scott Morton reported serving as a general antitrust consultant to and providing general antitrust testimony for Charles River Associates; and being employed by the US Department of Justice.

\section{REFERENCES}

1. Institute of Medicine. Crossing the Quality Chasm: A New Health System for the 21st Century. Washington, DC: Institute of Medicine; 2001.

2. Brill S. Bitter pill: why medical bills are killing us. Time. March 4, 2013;181(3):16-55.

3. American Hospital Association. Data from Chartbook. http://www.aha.org/research/reports /tw/chartbook/ch4.shtml. Accessed October 3, 2013.

4. Wikipedia. Herfindahl Index. http://en.wikipedia .org/wiki/Herfindahl_index. Accessibility verified October 16, 2013.

5. US Department of Justice; Federal Trade Commission. Horizontal merger guidelines. http://ftc.gov/os/2010/08/100819hmg.pdf. Accessibility verified October 10, 2013.

6. Irving Levin Associates. The 2012 Health Care Services Acquisition Report, 18th edition. http://www.levinassociates.com/har18order. Accessibility verified October 10, 2013.

7. Gaynor M. Health care industry consolidation [statement before the Committee on Ways and Means Health Subcommittee, US House of Representatives]. http://waysandmeans.house.gov /uploadedfiles/gaynor_testimony_9-9-11_final.pdf. Accessibility verified October 10, 2013.

8. Medical Group Management Association. Physician Compensation and Production Survey. Englewood, CO: Medical Group Management Association; 2012.

9. Steingart D, Goldstein L; Moody's Investors Service. US not-for-profit healthcare outlook remains negative for 2013. https://www.moodys .com/research/Moodys-Outlook-for-US-not-for -profit-hospitals-remains-negative--PR_264373. Accessed October 3, 2013.

10. Wikipedia. Bond credit rating. http://en.wikipedia.org/wiki/Bond_credit_rating. Accessed October 3, 2013.

11. Bazzoli GJ, Brewster LR, Liu G, Kuo S. Does US hospital capacity need to be expanded? Health Aff. 2003;22(6):40-54

12. Ho K. Insurer-provider networks in the medical care market. Am Econ Rev. 2009;99(1):393-430.

13. Congressional Budget Office. Letter to the Honorable Nancy Pelosi, March 20, 2010. http://www.cbo.gov/sites/default/files/cbofiles /ftpdocs/113xx/doc11379/amendreconprop.pdf. Accessibility verified October 10, 2013.

14. Kaiser Family Foundation. Status of state action on the Medicaid expansion decision, as of September 30, 2013. http://kff.org/health-reform /state-indicator/state-activity-around-expanding -medicaid-under-the-affordable-care-act/. Accessibility verified October 10, 2013.

15. Birkmeyer JD, Siewers AE, Finlayson EV, et al. Hospital volume and surgical mortality in the United States. N Engl J Med. 2002;346(15):11281137.

16. Birkmeyer JD, Stukel TA, Siewers AE, et al Surgeon volume and operative mortality in the United States. N Engl J Med. 2003;349(22):21172127.

17. Fisher ES, McClellan MB, Bertko J, et al. Fostering accountable health care. Health Aff (Millwood). 2009;28(2):w219-w231.
18. Dranove D, Lindrooth R. Hospital consolidation and costs. J Health Econ. 2003;22(6):983-997.

19. Harrison TD. Do mergers really reduce costs? Econ Inq. 2011;49(4):1054-1069.

20. Sloan FA. Not-for-profit ownership and hospital behavior. http://lingli.ccer.edu.cn/ahe2012 /Week6/Chapter21.pdf. Accessibility verified October 10, 2013.

21. Office of Attorney General Martha Coakley. Examination of health care cost trends and cost drivers. http://www.mass.gov/ago/docs/healthcare /2011-hcctd.pdf. Accessed October 3, 2013.

22. Ladapo JA, Horwitz JR, Weinstein MC, et al. Adoption and spread of new imaging technology. Health Aff (Millwood). 2009;28(6):w1122-w1132.

23. Christensen CM. The Innovator's Prescription: $A$ Disruptive Solution for Health Care. Columbus, $\mathrm{OH}$ : McGraw-Hill; 2008.

24. Stewart JB. Antitrust suit is simple calculus. http://www.nytimes.com/2011/09/10/business /att-and-t-mobile-merger-is-a-textbook-case.html ?pagewanted=all\&_r=3\&. Accessed October 3, 2013.

25. Federal Trade Commission; Department of Justice. Statement of antitrust enforcement policy regarding accountable care organizations participating in the Medicare Shared Savings Program, 2011. http://www.ftc.gov/os/fedreg/2011 /10/111020aco.pdf. Accessed October 17, 2013.

26. Kendall B. FTC gets more muscle in policing hospital mergers. http://online.wsj.com/news /articles/SB1000142412788732349510457831404 1654081664. Accessed October 3, 2013.

27. Emanuel EJ. The Arkansas innovation. http://opinionator.blogs.nytimes.com/2012/09/05 /the-arkansas-innovation/?_r=0. Accessed October 3, 2013.

28. Stecker EC. The Oregon ACO experiment-bold design, challenging execution. N Engl J Med. 2013;368(11):982-985.

29. Gosline A, Rodman E; Blue Cross Blue Shield Foundation. Summary of chapter 224 of the acts of 2012. http://bluecrossmafoundation.org/sites /default/files/download/publication/Chapter \%20224\%20summary_1.pdf. Accessibility verified October 10, 2013. 